\title{
Comparative dosimetric findings using accelerated partial breast irradiation across five catheter subtypes
}

Zaker Rana, Nadim M. Nasr, Huaying Ji, Virginia Lorio, Stephanie Akbari, Molly Sebastian, Mami Martin and Robert L. Hong ${ }^{*}$

\begin{abstract}
Purpose: Accelerated partial breast irradiation (APBI) with balloon and strut adjusted volume implants (SAVI) show promising results with excellent tumor control and minimal toxicity. Knowing the factors that contribute to a high skin dose, rib dose, and $\mathrm{D}_{95}$ coverage may reduce toxicity, improve tumor control, and help properly predict patient outcomes following APBI.

Methods and materials: A retrospective analysis of 594 patients treated with brachytherapy based APBI at a single institution from May 2008 to September 2014 was grouped by applicator subtype. Patients were treated to a total of 34 Gy (3.4 Gy x 10 fractions over 5 days delivered BID) targeting a planning target volume (PTV) $1.0 \mathrm{~cm}$ beyond the lumpectomy cavity using a high dose rate source.

Results: SAVI devices had the lowest statistically significant values of $D_{\max }$ Skin $(81.00 \pm 29.83)$, highest values of $D_{90}$ $(101.50 \pm 3.66)$, and $D_{95}(96.09 \pm 4.55)$. SAVI-mini devices had the lowest statistically significant values of $D_{\max } R i b$ $(77.66 \pm 32.92)$ and smallest $V_{150}(18.01 \pm 3.39)$. Multi-lumen balloons were able to obtain the smallest $V_{200}(5.89 \pm$ 2.21). Strut-based applicators were more likely to achieve a $D_{\max } S k i n$ and a $D_{\max }$ Rib less than or equal to $100 \%$. The effect of PTV on $V_{150}$ showed a strong positive relationship $(p<.001)$. PTV and $D_{\max }$ Skin showed a weak negative relationship in multi-lumen applicators $(p=.016)$ and SAVI-mini devices $(p<.001)$. PTV and Dmax Rib showed a weak negative relationship in multi-lumen applicators $(p=.009)$, SAVI devices $(p<.001)$, and SAVI-mini devices $(p<.001)$.

Conclusion: PTV volume is strongly correlated with $V_{150}$ in all devices and $V_{200}$ in strut based devices. Larger PTV volumes result in greater $V_{150}$ and $V_{200}$, which could help predict potential risks for hotspots and resulting toxicities in these devices. PTV volume is also weakly negatively correlated with max skin dose and max rib dose, meaning that as the PTV volumes increase one can expect slightly smaller max skin and rib doses. Strut based applicators are significantly more effective in keeping skin and rib dose constraints under 125 and $100 \%$ when compared to any balloon based applicator.
\end{abstract}

Keywords: APBI, brachytherapy, Mammosite, Contura, Savi

\section{Background}

Accelerated partial breast irradiation (APBI) has gained popularity as an alternative option to deliver adjuvant radiation therapy (RT) after lumpectomy in select patient populations with early stage breast cancer [1]. Several different forms of RT can be used to deliver APBI, including interstitial multicatheter brachytherapy, balloon catheter

\footnotetext{
*Correspondence: rhong@virginiahospitalcenter.com

Department of Radiation Oncology, Virginia Hospital Center, 1701 N George
} Mason Dr, Arlington, VA 22205, USA

brachytherapy, intraoperative radiation therapy, and conformal external beam radiation therapy [2]. Initial data has been reported using interstitial multicatheter brachytherapy, a technique that uses image guidance for the insertion of multiple afterloading catheters around the lumpectomy cavity, resulting in excellent target coverage and conformality [3-6]. Despite 10-year interstitial multicatheter brachytherapy results showing a local control rate $\geq 95 \%$, and excellent cosmetic outcomes in $90 \%$ of patients, physician acceptance has been slow $[7-10,6]$. 
The slow acceptance is partly due to the high degree of technical skill required for a successful interstitial implant $[3,11]$.

The MammoSite Single-Lumen (MS-SL) applicator (Hologic Inc, Bedford, MA) was introduced to simplify application and make results reproducible. The MammoSite catheter is composed of a $15 \mathrm{~cm}$ double-lumen catheter, that is $6 \mathrm{~mm}$ in diameter, and connected to a silicone balloon. The balloon is inflated to a size that completely fills the lumpectomy cavity and the prescription radiation dose is inserted through the catheter into the balloon [2]. A minimum balloon-to-skin distance of $5 \mathrm{~mm}$ is required with a threshold of at least $7 \mathrm{~mm}$ strongly recommended, as longer skin distance is associated with improved cosmesis [12-14]. MammoSite has been shown to be effective with low local recurrence rates and toxicity rates in both single institutional experiences and large multi-institutional experiences, like the American Society of Breast Surgeons MammoSite registry trial $[15,16]$. Patients with small breasts or upperinner quadrant tumors are not eligible for MS-SL due to the balloon surface being too close to the skin. Furthermore, since the device contains a single central source channel, geometry is fixed and dose optimization is limited $[17,18]$.

In order to eliminate dosimetric limitations seen in single lumen devices, Hologic introduced a MammoSite Multi-lumen (MS-ML) device and the Contura Multi-Lumen Balloon (Bard Biopsy Systems, Tempe, AZ) was developed. The MS-ML device has fewer outer lumens ( 3 vs. 4 ) with a shorter offset ( $3 \mathrm{~mm}$ vs. $5 \mathrm{~mm}$ ) from the central lumen when compared with the Contura device, but the two devices have been shown to produce a clinically comparable plan [19]. The outer lumens provide additional source positions and better dose flexibility when compared with a single-catheter approach. Multi-lumen catheters have also shown improvements in rib doses, skin doses, and PTV-EVAL coverage, when compared to singlelumen devices [20].

While multicatheter brachytherapy provides superior versatility and dosimetric conformity, they also require multiple skin incisions for placement. Hybrid brachytherapy devices were developed to provide dosimetric advantages while maintaining the simplicity and aesthetics of single-catheter breast brachytherapy devices [2]. The Strut Adjusted Volume Implant (SAVI) device (Cianna Medical, AlisoViejo, CA) is placed into a lumpectomy cavity through a single incision. The SAVI applicator itself has a central catheter as well as 6,8 , or 10 peripheral catheters that are expanded outwards to the periphery of the lumpectomy cavity after insertion [21]. The central and peripheral catheters contain a large number of potential dwell positions for the radiation source and are in direct contact with the lumpectomy cavity edge, providing flexibility in dose distribution [22].

APBI using balloon and strut-based applicators show promising results with excellent tumor control and minimal toxicity [23]. A higher dose to $95 \%$ of the planning target volume (D95) is important in achieving tumor control [24]. Achieving better cosmetic outcomes and reducing toxicity requires reduction in normal tissue exposure. Telangiectasia development has been shown to be a function of skin dose. The Virginia Commonwealth University experience, Contura phase IV registry trial, and recommendations in the ongoing NSABP-B39 protocol proposed skin consraints of $\leq 120, \leq 125$, and $\leq 145 \%$ $[25,3]$. However, recently published data suggest that skin doses $\geq 100 \%$ may represent a stronger predictor of late telangiectasia [23].

Knowing the factors that contribute to a high skin dose, rib dose, V150, V200, and D95 coverage may reduce toxicity, improve tumor control, and help properly predict patient outcomes following APBI. We present here our single-institution dosimetric performance with Mammosite, Contura, and SAVI APBI. We further characterize dosimetric correlates to reduce toxicity and maximize cosmetic preservation.

\section{Methods and materials}

A total of 594 patients, with localized breast cancer treated with brachytherapy based APBI at a single institution from May 2008 to September 2014, were retrospectively reviewed as part of a prospectively maintained institutional database. Due to the retrospective nature of this study, it was granted an exemption in writing by the Virginia Hospital Center IRB. Of the 594 patients, there were 496 strut based implants, including SAVI 6-1 mini, 6-1, 8-1, and 10-1 devices, but because of SAVI 6-1 mini's unique size it was separated into its own group. Multi-catheter balloon implants consisted of 54 Contura devices and 10 MammoSite mulit-lumen devices. Because the two devices have been shown to produce similar plans, they were combined into one multi-lumen balloon subgroup. Categories used for statistical analysis included 243 SAVI devices, 253 SAVI 6-1 mini devices, 64 multi-lumen balloons, and 34 Mammosite singlelumen balloons.

Generally inclusion criteria for APBI were in accordance with the American Society of Breast Surgeons (ASBS) and the American Society for Radiation Oncology (ASTRO): invasive carcinoma or ductal carcinoma in situ, tumor $<3 \mathrm{~cm}$, negative microscopic surgical margins, negative lymph nodes, and age 45 or older.

Patients were treated to a total of 34 Gy (3.4 Gy x 10 fractions over 5 days delivered BID) targeting a PTV $1 \mathrm{~cm}$ beyond the lumpectomy cavity using a high dose rate source. Minimum treatment planning goals for the 
Table 1 Baseline patient treatment characteristics

\begin{tabular}{lll}
\hline & & Patients (N=594) \\
\hline Age (y/o) & Median 63 (37-92) & \\
& $>60, \mathrm{n}(\%)$ & $342(57.6 \%)$ \\
& $50-60, \mathrm{n}(\%)$ & $173(29.1 \%)$ \\
& $>40-50, \mathrm{n}(\%)$ & $78(13.1 \%)$ \\
& $<40, \mathrm{n}(\%)$ & $1(0.2 \%)$ \\
Tumor location, $\mathrm{n}(\%)$ & Left breast & $297(50.0 \%)$ \\
& Right breast & $297(50.0 \%)$ \\
Tumor Size (mm) & Median & 13 \\
Grade & Range & $2-25$ \\
& Median & 2 \\
& Range & $1-3$ \\
\hline
\end{tabular}

planning target volume were initially D90 >90\%; in October 2011, PTV coverage goals were adjusted to $\mathrm{D}_{95}>95 \%$. Size of the planning target volume, absolute volume of the tissue receiving $150 \%$ of the prescription dose $\left(\mathrm{V}_{150}\right)$, and volume of tissue receiving $200 \%$ (V200), were evaluated. $3 \mathrm{D}$ treatment planning system was used to obtain the maximal point doses delivered to the skin and chest wall.

Statistical analysis was performed with SPSS v22.0 (SPSS Inc, Chicago, IL). Statistical significance was defined as $p<.05$. Multiple analysis-of-variance (MANOVA) was performed to search for possible differences between catheter subtypes. Dosimetric parameters were then compared across catheter subtype using Student's $t$-test $(\alpha<0.05)$. Multiple logistic regression with backward elimination was used in the multivariate analysis to search for possible predicting factors for maximum skin dose, maximum rib dose, and D95. Pearson's correlation coefficient was used to see PTV's effect on $D_{90}, D_{95}, V_{150}, V_{200}, D_{\max }$ Skin, and $D_{\max }$ Rib. Specifically, the basis of this analysis was to determine if larger PTV volumes would cause an increase in maximum doses and potential toxicities. A strong relationship was defined as an $\mathrm{r}$-value greater than 0.5 or less than- 0.5 with $p<.05$. A weak relationship was defined as an $\mathrm{r}$-value between 0.25 and 0.5 or -0.25 and -0.5 with $p<.05$.

\section{Results}

The baseline characteristics for included patients $(n=594)$ are shown in Table 1 . The mean values with the standard deviations of achieved dosimetric characteristics are shown in Table 2 and Fig. 1. Student's $t$-test was used to compare the dosimetric characteristics across each type of APBI device (Tables 3, 4 and 5).

\section{$D_{\text {max }}$ Skin}

The lowest values of $\mathrm{D}_{\max }$ Skin were obtained in the SAVI devices $(81.00 \pm 29.83)$. This mean difference was significantly less than single-lumen balloon applicators $(-27.56, p<.001)$, multi-lumen balloon applicators $(-33.09, p<.001)$, and SAVI-mini devices $(-15.20$, $p<.001$ ) (Table 3). Strut-based applicators (SAVI: $0.8 \%$, SAVI-mini: $4.0 \%)$ were much less likely to receive a $\mathrm{D}_{\max }$ Skin greater than or equal to $125 \%$, when compared to single-lumen $(32.4 \%)$ and multilumen balloon applicators (31.3 \%) (Fig. 2). Strutbased applicators were also more likely to achieve a $\mathrm{D}_{\text {max }}$ Skin less than or equal to $100 \%$ with SAVI devices achieving this $65.8 \%$ of the time.

\section{$D_{\text {max }}$ Rib}

The lowest values of $D_{\max }$ Rib were seen in the SAVI-mini devices $(77.66 \pm 32.92)$. The mean difference in SAVI-mini devices was statistically significant when compared to single-lumen balloon applicators $(-36.34, p<.001)$ and multi-lumen balloon applicators $(-27.37, p<.001)$. There was no statistically significant difference in $D_{\max } R i b$ when comparing SAVI-mini devices with SAVI devices. Strut-based devices were able to achieve a $D_{\max }$ Rib less than or equal to $100 \%$ in $70 \%$ of patients treated, which was more frequent than the single-lumen balloon applicators $(35.3 \%)$ and multi-lumen balloon applicators (43.8\%) (Fig. 3).

\section{$D_{90}$ and $D_{95}$}

SAVI devices had the highest values of $\mathrm{D}_{90}(101.50 \pm$ 3.66) and $\mathrm{D}_{95}(96.09 \pm 4.55)$. When compared to multilumen balloon applicators, strut-based devices had a

Table 2 Dose distribution parameters (mean values and standard deviation) across catheter subtype

\begin{tabular}{llllll}
\hline & Single-lumen $(n=34)$ & Multi-lumen $(n=64)$ & SAVI $(n=243)$ & SAVI-mini $(n=253)$ & All Devices $(n=594)$ \\
\hline$D_{90}(\%)$ & $97.33 \pm 4.75$ & $94.16 \pm 6.54$ & $101.50 \pm 3.66$ & $100.45 \pm 5.48$ & $100.02 \pm 5.40$ \\
$D_{95}(\%)$ & $95.74 \pm 7.47$ & $90.06 \pm 7.90$ & $96.09 \pm 4.55$ & $94.12 \pm 6.61$ & $94.58 \pm 6.33$ \\
$D_{\max }$ Skin & $108.56 \pm 30.44$ & $114.09 \pm 34.10$ & $81.00 \pm 29.83$ & $96.20 \pm 27.17$ & $92.62 \pm 31.26$ \\
$D_{\max }$ Rib & $114 \pm 43.82$ & $105.03 \pm 47.80$ & $78.06 \pm 32.87$ & $77.66 \pm 32.92$ & $82.85 \pm 37.16$ \\
$V_{150}\left(\mathrm{~cm}^{3}\right)$ & $29.86 \pm 5.44$ & $23.44 \pm 5.98$ & $24.32 \pm 4.69$ & $18.01 \pm 3.39$ & $21.85 \pm 5.66$ \\
$V_{200}\left(\mathrm{~cm}^{3}\right)$ & $6.34 \pm 2.17$ & $5.89 \pm 2.21$ & $10.74 \pm 2.88$ & $9.28 \pm 1.87$ & $9.34 \pm 2.87$ \\
PTV $\left(\mathrm{cm}^{3}\right)$ & $94.62 \pm 14.72$ & $80.88 \pm 19.55$ & $60.15 \pm 12.89$ & $40.36 \pm 7.13$ & $55.93 \pm 20.14$ \\
\hline
\end{tabular}



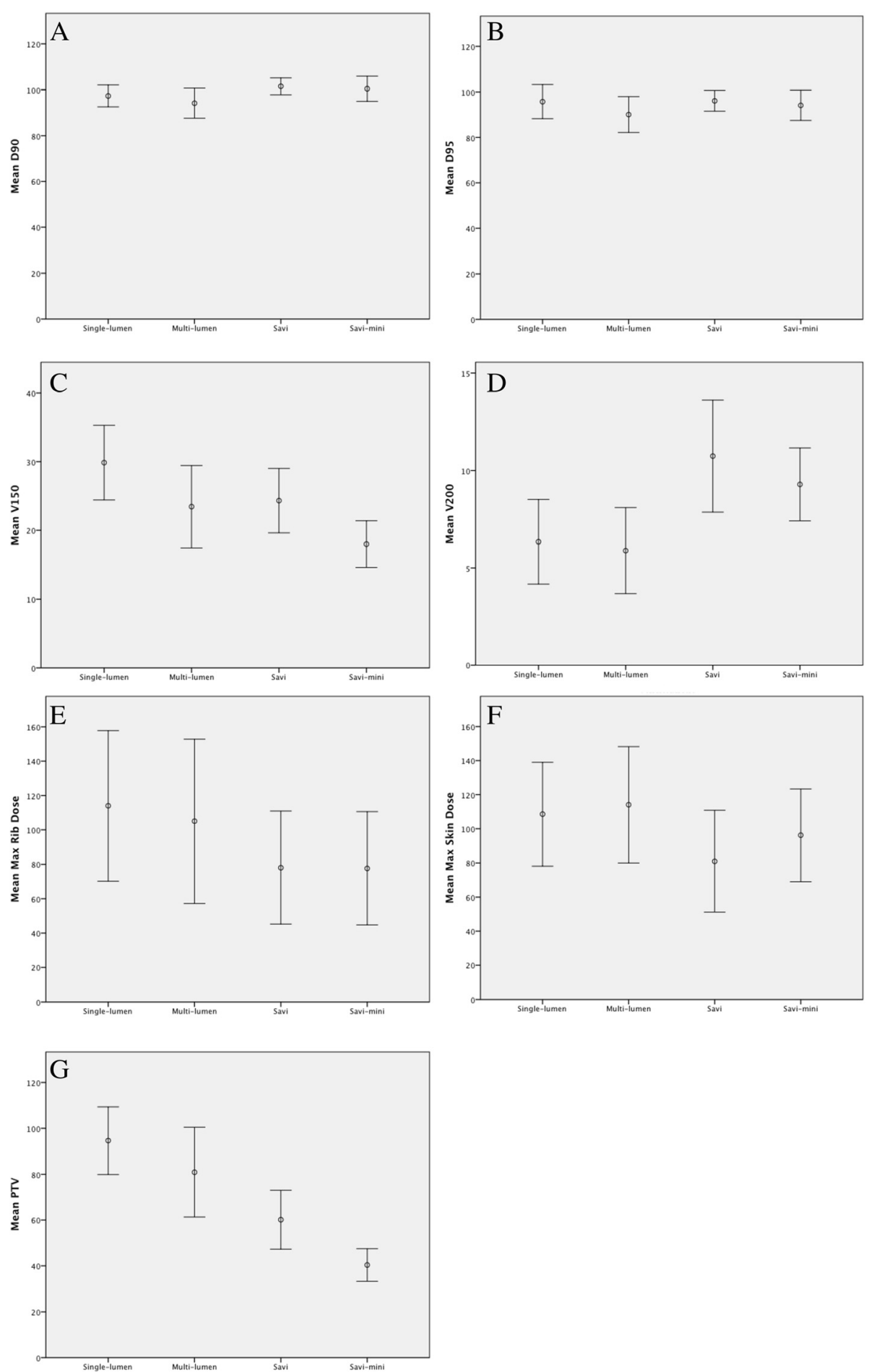

Fig. 1 Mean dosimetric values +/-one standard deviation across APBI device (a) $D_{90}(\mathbf{b}) D_{95}(\mathbf{c}) V_{150}(\mathbf{d}) V_{200}(\mathbf{e}) D_{\max } R i b(\mathbf{f}) D_{\max } S k i n(\mathbf{g}) P T V$

statistically significant greater $\mathrm{D}_{90}$ mean difference (7.34, $p<.001)$ and $\mathrm{D}_{95}$ mean difference $(6.02, p<.001)$ (Table 4). However, the difference was not statistically significant different when compared to single-lumen devices.

\section{$\mathrm{V}_{\mathbf{1 5 0}}$ and $\mathrm{V}_{\mathbf{2 0 0}}$}

SAVI-mini devices obtained the smallest $\mathrm{V}_{150}(18.01 \pm$ 3.39) and this mean difference was significantly smaller than single-lumen $(-11.85, p<.001)$, multi-lumen $(-5.44$, $p<.001)$, and SAVI devices $(-6.31, p<.001)$ (Table 5). 
Table 3 Comparison of skin and rib doses between APBI devices

\begin{tabular}{|c|c|c|c|c|c|}
\hline $\begin{array}{l}\text { Dependent } \\
\text { Variable }\end{array}$ & (I) Applicator & (J) Applicator & Mean Difference (I-J) & Std. Error & $p$ \\
\hline \multirow[t]{12}{*}{$D_{\max }$ Skin } & \multirow[t]{3}{*}{ Single-lumen } & Multi-lumen & -5.5242 & 6.20960 & .374 \\
\hline & & Savi & 27.5618 & 5.35769 & $<.001$ \\
\hline & & Savi-mini & 12.3611 & 5.34468 & .021 \\
\hline & \multirow[t]{3}{*}{ Multi-lumen } & Single-lumen & 5.5242 & 6.20960 & .374 \\
\hline & & Savi & 33.0860 & 4.11108 & $<.001$ \\
\hline & & Savi-mini & 17.8853 & 4.09411 & $<.001$ \\
\hline & \multirow[t]{3}{*}{ Savi } & Single-lumen & -27.5618 & 5.35769 & $<.001$ \\
\hline & & Multi-lumen & -33.0860 & 4.11108 & $<.001$ \\
\hline & & Savi-mini & -15.2007 & 2.62820 & $<.001$ \\
\hline & \multirow[t]{3}{*}{ Savi-mini } & Single-lumen & -12.3611 & 5.34468 & .021 \\
\hline & & Multi-lumen & -17.8853 & 4.09411 & $<.001$ \\
\hline & & Savi & 15.2007 & 2.62820 & $<.001$ \\
\hline \multirow[t]{12}{*}{$D_{\max } R i b$} & \multirow[t]{3}{*}{ Single-lumen } & Multi-lumen & 8.9750 & 7.52486 & .233 \\
\hline & & Savi & 35.9376 & 6.49250 & $<.001$ \\
\hline & & Savi-mini & 36.3416 & 6.47673 & $<.001$ \\
\hline & \multirow[t]{3}{*}{ Multi-lumen } & Single-lumen & -8.9750 & 7.52486 & .233 \\
\hline & & Savi & 26.9626 & 4.98185 & $<.001$ \\
\hline & & Savi-mini & 27.3666 & 4.96129 & $<.001$ \\
\hline & \multirow[t]{3}{*}{ Savi } & Single-lumen & -35.9376 & 6.49250 & $<.001$ \\
\hline & & Multi-lumen & -26.9626 & 4.98185 & $<.001$ \\
\hline & & Savi-mini & .4040 & 3.18487 & .899 \\
\hline & \multirow[t]{3}{*}{ Savi-mini } & Single-lumen & -36.3416 & 6.47673 & $<.001$ \\
\hline & & Multi-lumen & -27.3666 & 4.96129 & $<.001$ \\
\hline & & Savi & -.4040 & 3.18487 & .899 \\
\hline
\end{tabular}

When looking at $\mathrm{V}_{200}$, multi-lumen balloons were able to obtain the smallest volume $(5.89 \pm 2.21)$. This volume was significantly smaller than SAVI $(-4.85, p<.001)$ and SAVI-mini devices $(-3.40, p<.001)$, but when comparing $\mathrm{V}_{200}$ obtained in multi-lumen and single-lumen applicators there was no significant difference.

\section{PTV}

PTV was statistically significantly smaller when SAVI and SAVI-mini devices were used as opposed to singlelumen and multi-lumen balloon applicators (Tables 2 and 5). The effect of PTV on dosimetric characteristics was observed using Pearson's correlation coefficient in order to determine if larger PTV volumes resulted in greater maximum doses. When looking at all the devices together $(n=594), V_{150}$ was the only dosimetric constraint to show a strong positive relationship with PTV $(r=.783, p<.001)$ (Table 6). This strong positive relationship between PTV and $\mathrm{V}_{150}$ was also observed when devices were stratified between SAVI $(r=.808, p<.001)$, SAVImini devices $(r=.826, p<.001)$, multi-lumen applicators $(r=.547, p<.001)$, and single-lumen applicators $(r=.513$, $p<.001)$. PTV and $\mathrm{V}_{200}$ showed a strong positive relationship in SAVI-mini devices $(r=.586, p<.001)$ and a weak positive relationship in SAVI devices $(r=.266, p<.001)$. PTV and $\mathrm{D}_{\max }$ Skin showed a weak negative relationship in multi-lumen applicators $(r=-.301, p=.016)$ and SAVI-mini devices $(r=-.350, \quad p<.001)$. PTV and $\mathrm{D}_{\max } \mathrm{Rib}$ showed a weak negative relationship in multi-lumen applicators $(r=-.325, p=.009)$, SAVI devices $(r=.407, p<.001)$, and SAVI-mini devices $(r=-.297, p<.001)$. PTV had a weak positive relationship with $\mathrm{D}_{90}$ in multi-lumen balloon applicators $(r=.388, p=.002)$ and SAVI-mini devices $(r=.335, p<.001)$. PTV also had a weak positive relationship with $\mathrm{D}_{95}$ in multi-lumen balloon applicators $(r=.382$, $p=.002)$ and SAVI-mini devices $(r=.405, p<.001)$.

Of the 594 patients treated, 139 of the patients were followed for three years after treatment. There were 3 local failures $(2.2 \%)$ after three years resulting in a local control rate of $97.8 \%$. There were a total of 2 contralateral failures (1.4\%). Two and three year disease free survival rate were 98.8 and $96.3 \%$ respectively. 
Table 4 Comparison of $\mathrm{D}_{90}$ and $\mathrm{D}_{95}$ between APBI devices

\begin{tabular}{|c|c|c|c|c|c|}
\hline & (I) Applicator & (J) Applicator & $\begin{array}{l}\text { Mean Difference } \\
(I-J)\end{array}$ & Std. Error & $p$ \\
\hline \multirow[t]{12}{*}{$D_{90}$} & \multirow[t]{3}{*}{ Single-lumen } & Multi-lumen & 3.1699 & 1.04264 & .002 \\
\hline & & Savi & -4.1677 & .89960 & $<.001$ \\
\hline & & Savi-mini & -3.1167 & .89741 & .001 \\
\hline & \multirow[t]{3}{*}{ Multi-lumen } & Single-lumen & -3.1699 & 1.04264 & .002 \\
\hline & & Savi & -7.3376 & .69028 & $<.001$ \\
\hline & & Savi-mini & -6.2866 & .68743 & $<.001$ \\
\hline & \multirow[t]{3}{*}{ Savi } & Single-lumen & 4.1677 & .89960 & $<.001$ \\
\hline & & Multi-lumen & 7.3376 & .69028 & $<.001$ \\
\hline & & Savi-mini & 1.0510 & .44129 & .018 \\
\hline & \multirow[t]{3}{*}{ Savi-mini } & Single-lumen & 3.1167 & .89741 & .001 \\
\hline & & Multi-lumen & 6.2866 & .68743 & $<.001$ \\
\hline & & Savi & -1.0510 & .44129 & .018 \\
\hline \multirow[t]{12}{*}{$D_{95}$} & \multirow[t]{3}{*}{ Single-lumen } & Multi-lumen & 5.6730 & 1.29051 & $<.001$ \\
\hline & & Savi & -.3506 & 1.11346 & .753 \\
\hline & & Savi-mini & 1.6171 & 1.11076 & .146 \\
\hline & \multirow[t]{3}{*}{ Multi-lumen } & Single-lumen & -5.6730 & 1.29051 & $<.001$ \\
\hline & & Savi & -6.0236 & .85439 & $<.001$ \\
\hline & & Savi-mini & -4.0559 & .85086 & $<.001$ \\
\hline & \multirow[t]{3}{*}{ Savi } & Single-lumen & .3506 & 1.11346 & .753 \\
\hline & & Multi-lumen & 6.0236 & .85439 & $<.001$ \\
\hline & & Savi-mini & 1.9677 & .54620 & $<.001$ \\
\hline & \multirow[t]{3}{*}{ Savi-mini } & Single-lumen & -1.6171 & 1.11076 & .146 \\
\hline & & Multi-lumen & 4.0559 & .85086 & $<.001$ \\
\hline & & Savi & -1.9677 & .54620 & $<.001$ \\
\hline
\end{tabular}

\section{Discussion}

Our current report documents the ability to achieve dosimetric prescription goals across various applicators in patients treated with APBI. Low maximum skin dose and the small high-dose volumes are crucial in maintaining good cosmetic outcomes [2, 26-30]. In HDR interstitial brachytherapy volumes receiving 150 and $200 \%$ of prescription dose have been shown to correlate with toxicity [31]. Because of the link between toxicity and dosimetric parameters, the NSABP B39/RTOG 04-13 requires $V_{150}$ to be $\leq 70 \mathrm{~cm}^{3}$ and $V_{200}$ to be less than $20 \mathrm{~cm}^{3}$ in multi-catheter treatment and $V_{150}$ to be $\leq$ $50 \mathrm{~cm}^{3}$ and $\mathrm{V}_{200}$ to be less than $10 \mathrm{~cm}^{3}$ in MammoSite balloon treatment.

It has been established that multi-lumen applicators allow for better optimization of dose distribution in the treatment area, minimizing the risk to nontarget areas [32, 31, 33]. However, this was not always the case in our data set as multi-lumen balloon applicators showed no statistically significant advantage to singlelumen balloon applicators when comparing $\mathrm{D}_{\max }$ Skin
Table 5 Comparison of PTV, V150, and V200 between APBI devices

\begin{tabular}{|c|c|c|c|c|c|}
\hline & (I) Applicator & (J) Applicator & $\begin{array}{l}\text { Mean } \\
\text { Difference }(I-J)\end{array}$ & Std. Error & $p$ \\
\hline \multirow[t]{13}{*}{ PTV } & \multirow[t]{4}{*}{ Single-lumen } & Multi-lumen & 13.7353 & 2.53559 & $<.001$ \\
\hline & & Savi & 34.4664 & 2.18772 & $<.001$ \\
\hline & & Savi-mini & 54.2576 & 2.18241 & $<.001$ \\
\hline & & Multi-lumen & 13.7353 & 2.53559 & $<.001$ \\
\hline & \multirow[t]{3}{*}{ Multi-lumen } & Single-lumen & -13.7353 & 2.53559 & $<.001$ \\
\hline & & Savi & 20.7310 & 1.67869 & $<.001$ \\
\hline & & Savi-mini & 40.5222 & 1.67176 & $<.001$ \\
\hline & \multirow[t]{3}{*}{ Savi } & Single-lumen & -34.4664 & 2.18772 & $<.001$ \\
\hline & & Multi-lumen & -20.7310 & 1.67869 & $<.001$ \\
\hline & & Savi-mini & 19.7912 & 1.07318 & $<.001$ \\
\hline & \multirow[t]{3}{*}{ Savi-mini } & Single-lumen & -54.2576 & 2.18241 & $<.001$ \\
\hline & & Multi-lumen & -40.5222 & 1.67176 & $<.001$ \\
\hline & & Savi & -19.7912 & 1.07318 & $<.001$ \\
\hline \multirow[t]{12}{*}{$V_{150}$} & \multirow[t]{3}{*}{ Single-lumen } & Multi-lumen & 6.4121 & .93452 & $<.001$ \\
\hline & & Savi & 5.5340 & .80631 & $<.001$ \\
\hline & & Savi-mini & 11.8479 & .80435 & $<.001$ \\
\hline & \multirow[t]{3}{*}{ Multi-lumen } & Single-lumen & -6.4121 & .93452 & $<.001$ \\
\hline & & Savi & -.8782 & 61870 & .156 \\
\hline & & Savi-mini & 5.4357 & 61615 & $<.001$ \\
\hline & \multirow[t]{3}{*}{ Savi } & Single-lumen & -5.5340 & .80631 & $<.001$ \\
\hline & & Multi-lumen & .8782 & 61870 & .156 \\
\hline & & Savi-mini & 6.3139 & .39553 & $<.001$ \\
\hline & \multirow[t]{3}{*}{ Savi-mini } & Single-lumen & -11.8479 & .80435 & $<.001$ \\
\hline & & Multi-lumen & -5.4357 & .61615 & $<.001$ \\
\hline & & Savi & -6.3139 & .39553 & $<.001$ \\
\hline \multirow[t]{12}{*}{$V_{200}$} & \multirow[t]{3}{*}{ Single-lumen } & Multi-lumen & .4523 & .50586 & .372 \\
\hline & & Savi & -4.4003 & .43646 & $<.001$ \\
\hline & & Savi-mini & -2.9443 & .43540 & $<.001$ \\
\hline & \multirow[t]{3}{*}{ Multi-lumen } & Single-lumen & -.4523 & .50586 & .372 \\
\hline & & Savi & -4.8526 & .33490 & $<.001$ \\
\hline & & Savi-mini & -3.3966 & .33352 & $<.001$ \\
\hline & \multirow[t]{3}{*}{ Savi } & Single-lumen & 4.4003 & .43646 & $<.001$ \\
\hline & & Multi-lumen & 4.8526 & .33490 & $<.001$ \\
\hline & & Savi-mini & 1.4560 & .21410 & $<.001$ \\
\hline & \multirow[t]{3}{*}{ Savi-mini } & Single-lumen & 2.9443 & .43540 & $<.001$ \\
\hline & & Multi-lumen & 3.3966 & .33352 & $<.001$ \\
\hline & & Savi & -1.4560 & .21410 & $<.001$ \\
\hline
\end{tabular}

or $\mathrm{D}_{\max }$ Rib. However, multi-lumen balloon applicators were able to achieve smaller high-dose volumes when compared to single-lumen balloon applicators.

Strut-based intracavitary devices showed a clear advantage in $\mathrm{D}_{90}, \mathrm{D}_{\max }$ Skin, and $\mathrm{D}_{\max }$ Rib, when compared to balloon-based applicators. Higher maximum doses in 


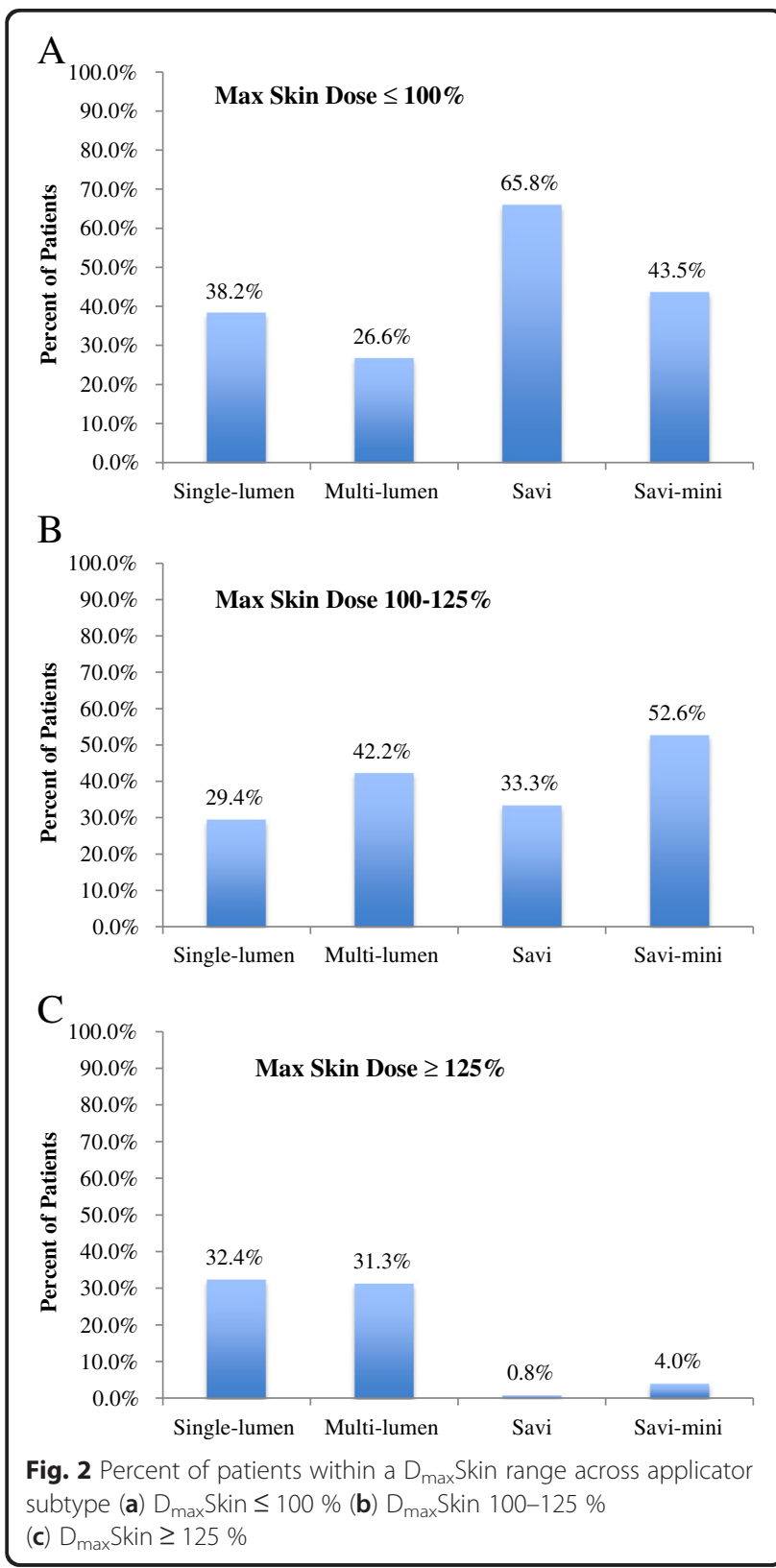

balloon applicators could be from confluent "hot spots" seen at the balloon surface [3]. Instead of a balloon, SAVI devices have a central catheter that is surrounded by multiple struts containing multiple dwell positions for the radioactive source. This design allows preferential treatment to the side of the cavity closest to the surgical margin and eliminates balloon surface "hot spots" [22]. The unique and flexible design could also account for the better $\mathrm{D}_{90}$ and $\mathrm{D}_{95}$. Additionally, in balloon-based applicators, seroma formation has been shown to be a function of radiation hot spots [34, 23].

Strut-based devices were significantly better at keeping the $\mathrm{D}_{\max }$ Skin and $\mathrm{D}_{\max }$ Rib, under the 125 and $100 \%$ thresholds. This may result in less skin and rib toxicity.

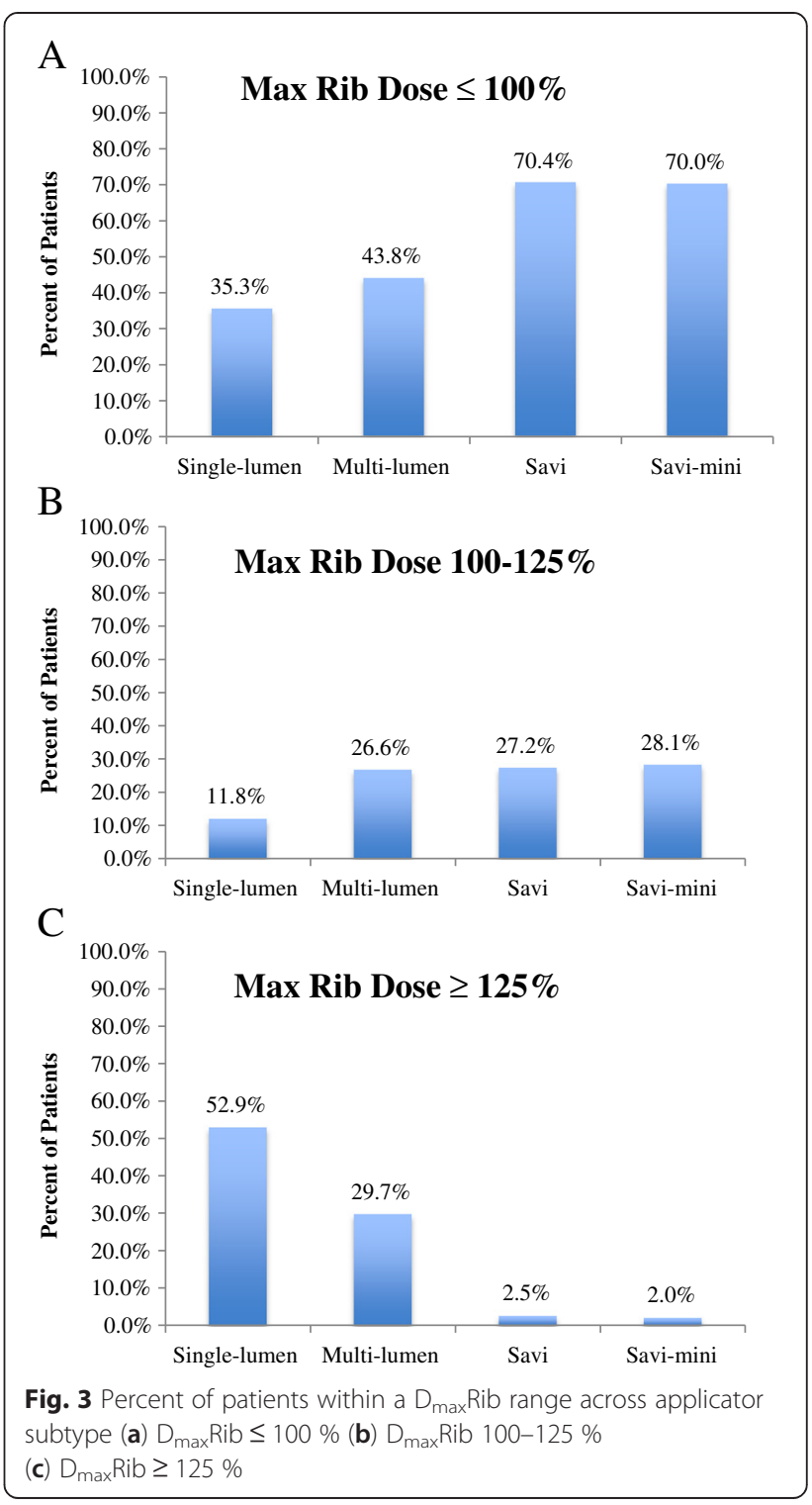

Higher doses to the ribs are associated with fractures and limiting this value can decrease its incidence [14]. Vargo et. al recently showed telangiectasia development to be a function of skin dose, where a skin dose $>100 \%$ was the strongest predictor for telangiectasia development [23]. Cuttino et al. also showed that the maximal dose delivered to the skin was significantly associated with the incidence of telangiectasia and moderate to severe fibrosis, especially when doses were $>120 \%$ of the prescription dose [3]. The higher $\mathrm{D}_{\max }$ Skin in singlelumen devices was expected as dose constraints are sometimes not feasible as single-channel balloon catheters may thin out the anterior tissue plane [35].

Our data was similar to Patel et. al, who showed strut-based intracavitary implants are associated with a significantly greater $V_{200}$ and smaller $V_{150}$ when 
Table 6 The Effect of PTV on $D_{90}, D_{95}, D_{\max }$ Skin, $D_{\max } R i b, V_{150}$, and $V_{200}$

\begin{tabular}{|c|c|c|c|c|c|c|c|c|c|c|}
\hline & Single-1 & & Multi-lu & & SAVI & & SAVI 6- & & Total & \\
\hline & $(n=34)$ & & $(n=64)$ & & $(n=243$ & & $(n=25$ & & $(n=59$ & \\
\hline & $r$ & $p$ & $r$ & $p$ & $r$ & $p$ & $r$ & $p$ & $r$ & $p$ \\
\hline PTV (cc) vs. $D_{90}$ & .236 & .180 & $.388^{*}$ & .002 & .072 & .263 & $.335^{*}$ & $<.001$ & $-.082^{*}$ & .046 \\
\hline PTV (cc) vs $D_{95}$ & .102 & .565 & $.382^{*}$ & .002 & $.129^{*}$ & .044 & $.405^{*}$ & $<.001$ & $.111^{*}$ & .007 \\
\hline PTV (cc) vs $D_{\max }$ Skin & -.153 & .388 & $-.301^{*}$ & .016 & -.056 & .384 & $-.350^{*}$ & $<.001$ & -.021 & .603 \\
\hline PTV (cc) vs $D_{\max } R i b$ & -.217 & .217 & $-.325^{*}$ & .009 & $-.407^{*}$ & $<.001$ & $-.297^{*}$ & $<.001$ & .020 & .626 \\
\hline PTV (cc) vs $V_{150}$ & $.513^{*}$ & .002 & $.547^{*}$ & $<.001$ & $.808^{*}$ & $<.001$ & $.826^{*}$ & $<.001$ & $.783^{*}$ & $<.001$ \\
\hline PTV (cc) vs $V_{200}$ & -.332 & .055 & -.176 & .163 & $.266^{*}$ & $<.001$ & $.586^{*}$ & $<.001$ & $-.125^{*}$ & .002 \\
\hline
\end{tabular}

Any relationship is demarcated with *. A strong relationship was defined as an r-value greater than 0.5 or less than -0.5 with $\mathrm{p}<.05$. A weak relationship was defined as an r-value between 0.25 and 0.5 or -0.25 and -0.5 with $p<.05$

compared to balloon implants [36]. A suboptimal cosmetic outcome and skin toxicity has been shown to be significantly associated with $\mathrm{V}_{150}$ and $\mathrm{V}_{200}$, and inversely related to the dose homogeneity index which is defined as $\left(1-\mathrm{V}_{150} / \mathrm{V}_{100}\right)$. The development of fat necrosis has also been shown to be associated with $V_{150}$ and $V_{200}$, while late subcutaneous toxicity has only shown associations with dose homogeneity index [31]. Even though clinical significance has not yet been established, the dose homogeneity index with SAVI is typically lower than those seen in interstitial or balloon brachytherapy [22]. $\mathrm{V}_{150}$ and $\mathrm{V}_{200}$ could also have to reach a specific threshold to result in toxicity. Cuttino et. al saw no association between outcomes and $V_{150}$ or $V_{200}$, but accounted for this because only $4 \%$ of their patient population exceeded a $V_{200}$ of $20 \mathrm{~cm}^{3}$ [3]. Our results were similar, as only one patient $(0.1 \%)$ exceeded a $V_{200}$ of $20 \mathrm{~cm}^{3}$.

Because strut-based devices were used on smaller PTVs we wanted to see how the PTV affected dosimetric parameters. The only strong correlation in all devices was seen between PTV and $V_{150}$ showing that with greater treatment volumes higher dose volumes should be expected. PTV and V200 also showed a strong correlation in SAVI-mini devices. PTV was weakly negatively correlated with max skin dose and max rib dose and weakly positively correlated with $D_{95}$ across the strut based and multi-channel balloon applicators. Because of this weak correlation it is hard to anticipate maximum doses to the skin and ribs by PTV alone. While our study had a minimum skin bridge of $5 \mathrm{~mm}$ for all patients, based on the correlation between smaller PTV and maximum skin dose the SAVI-mini may prove to be appropriate for those with less than $5 \mathrm{~mm}$ of skin distance. The variable of skin bridge was eliminated because we had a cutoff of $5 \mathrm{~mm}$. No patients experienced a fracture within the follow-up period within the contoured rib structures.
This study has several limitations. Because this study was a retrospective analysis there was a lack of standardization among patients. The group of patients receiving strut-based devices was also much larger than the patients receiving single-lumen or multi-lumen balloon applicators.

\section{Conclusion}

The data from this study shows PTV volume is strongly correlated with $V_{150}$ in all devices and $V_{200}$ in strut based devices. Larger PTV volumes result in greater $V_{150}$ and $V_{200}$, which could help predict potential risks for hotspots and resulting toxicities in these devices. PTV volume is also weakly negatively correlated with max skin dose and max rib dose, meaning that as the PTV volumes increase one can expect slightly smaller max skin and rib doses. Strut based applicators are significantly more effective in keeping skin and rib dose constraints under 125 and $100 \%$ when compared to any balloon based applicator and also achieve a significantly better $D_{90}$.

\section{Competing interests}

The authors declare that they have no competing interests.

\section{Authors' contributions}

ZR carried out the data analysis and drafted the manuscript. NN helped compile the data, was heavily involved in radiation treatment, and drafted the manuscript. HJ and VL compiled the data, put together the data in a spreadsheet, helped with data analysis, as well as editing the paper. SA, MS, and $\mathrm{MM}$, contributed to surgery, placement of the devices, and editing the final manuscript. $\mathrm{RH}$ conceived the study, participated in its design and coordination, treated the patients, and helped to draft the manuscript. All authors read and approved the final manuscript.

\section{Acknowledgements}

There are no further acknowledgements and no additional source of funding.

Received: 28 March 2015 Accepted: 17 July 2015

Published online: 31 July 2015

\section{References}

1. Sarin R. Partial-breast treatment for early breast cancer: emergence of a new paradigm. Nat Clin Pract Oncol. 2005;2(1):40-7. doi:10.1038/ncponc0071. 
2. Njeh CF, Saunders MW, Langton CM. Accelerated Partial Breast Irradiation (APBI): a review of available techniques. Radiat Oncol. 2010;5:90. doi:10.1186/1748-717X-5-90.

3. Cuttino LW, Heffernan J, Vera R, Rosu M, Ramakrishnan VR, Arthur DW. Association between maximal skin dose and breast brachytherapy outcome: a proposal for more rigorous dosimetric constraints. Int J Radiat Oncol Biol Phys. 2011;81(3):e173-7. doi:10.1016/j.jirobp.2010.12.023.

4. King TA, Bolton JS, Kuske RR, Fuhrman GM, Scroggins TG, Jiang XZ. Long-term results of wide-field brachytherapy as the sole method of radiation therapy after segmental mastectomy for $\mathrm{T}(\mathrm{is}, 1,2)$ breast cancer. Am J Surg. 2000;180(4):299-304.

5. Vicini FA, Baglan KL, Kestin LL, Mitchell C, Chen PY, Frazier RC, et al. Accelerated treatment of breast cancer. J Clin Oncol. 2001;19(7):1993-2001.

6. Polgar C, Fodor J, Major T, Nemeth G, Lovey K, Orosz Z, et al. Breastconserving treatment with partial or whole breast irradiation for low-risk invasive breast carcinoma-5-year results of a randomized trial. Int J Radiat Oncol Biol Phys. 2007;69(3):694-702. doi:10.1016/j.jijrobp.2007.04.022.

7. Antonucci JV, Wallace M, Goldstein NS, Kestin L, Chen P, Benitez P, et al. Differences in patterns of failure in patients treated with accelerated partial breast irradiation versus whole-breast irradiation: a matched-pair analysis with 10-year follow-up. Int J Radiat Oncol Biol Phys. 2009;74(2):447-52. doi:10.1016/j.jijrobp.2008.08.025.

8. Arthur DW, Winter K, Kuske RR, Bolton J, Rabinovitch R, White J, et al. A Phase II trial of brachytherapy alone after lumpectomy for select breast cancer: tumor control and survival outcomes of RTOG 95-17. Int J Radiat Oncol Biol Phys. 2008;72(2):467-73. doi:10.1016/j.jjobp.2007.12.056.

9. Kaufman SA, DiPetrillo TA, Price LL, Midle JB, Wazer DE. Long-term outcome and toxicity in a Phase $\mathrm{I} / \mathrm{I}$ trial using high-dose-rate multicatheter interstitial brachytherapy for T1/T2 breast cancer. Brachytherapy. 2007;6(4):286-92. doi:10.1016/j.brachy.2007.09.001.

10. Ott OJ, Hildebrandt G, Potter R, Hammer J, Lotter M, Resch A, et al. Accelerated partial breast irradiation with multi-catheter brachytherapy: Local control, side effects and cosmetic outcome for 274 patients. Results of the German-Austrian multi-centre trial. Radiother Oncol. 2007;82(3):281-6. doi:10.1016/j.radonc.2006.08.028.

11. Benitez PR, Keisch ME, Vicini F, Stolier A, Scroggins T, Walker A, et al. Five-year results: the initial clinical trial of MammoSite balloon brachytherapy for partial breast irradiation in early-stage breast cancer. Am J Surg. 2007;194(4):456-62. doi:10.1016/j.amjsurg.2007.06.010.

12. Dragun $A E$, Harper JL, Jenrette JM, Sinha D, Cole DJ. Predictors of cosmetic outcome following MammoSite breast brachytherapy: a single-institution experience of 100 patients with two years of follow-up. Int J Radiat Oncol Biol Phys. 2007:68(2):354-8. doi:10.1016/j.ijrobp.2006.12.014.

13. Niehoff $P$, Polgar $C$, Ostertag H, Major T, Sulyok Z, Kimmig B, et al. Clinical experience with the MammoSite radiation therapy system for brachytherapy of breast cancer: results from an international phase II trial. Radiother Oncol. 2006;79(3):316-20. doi:10.1016/j.radonc.2006.05.010.

14. Vicini F, Beitsch PD, Quiet CA, Keleher AJ, Garcia D, Snider Jr HC, et al. Three-year analysis of treatment efficacy, cosmesis, and toxicity by the American Society of Breast Surgeons MammoSite Breast Brachytherapy Registry Trial in patients treated with accelerated partial breast irradiation (APBI). Cancer. 2008;112(4):758-66. doi:10.1002/cncr.23227.

15. Khan AJ, Arthur D, Vicini F, Beitsch P, Kuerer H, Goyal S, et al. Six-year analysis of treatment-related toxicities in patients treated with accelerated partial breast irradiation on the American Society of Breast Surgeons MammoSite Breast Brachytherapy registry trial. Ann Surg Oncol. 2012;19(5):1477-83. doi:10.1245/s10434-011-2133-1.

16. Vicini F, Beitsch P, Quiet C, Gittleman M, Zannis V, Fine R, et al. Five-year analysis of treatment efficacy and cosmesis by the American Society of Breast Surgeons MammoSite Breast Brachytherapy Registry Trial in patients treated with accelerated partial breast irradiation. Int J Radiat Oncol Biol Phys. 2011;79(3):808-17. doi:10.1016/j.jirobp.2009.11.043.

17. Dickler A, Patel RR, Wazer D. Breast brachytherapy devices. Expert Rev Med Devices. 2009:6(3):325-33. doi:10.1586/erd.09.6.

18. Brashears JH, Dragun AE, Jenrette JM. Late chest wall toxicity after MammoSite breast brachytherapy. Brachytherapy. 2009:8(1):19-25. doi:10.1016/j.brachy.2008.07.007.

19. Kim Y, Trombetta M. Dosimetric evaluation of MammoSite ${ }^{\oplus}$ multi-lumen balloon applicator compared with contura ${ }^{\oplus}$ applicator for high dose rate (HDR) breast brachytherapy. Int J Radiat Oncol Biol Phys. 2011;81(2):902-3.
20. Brown $S$, McLaughlin M, Pope $K$, Haile $K$, Hughes $L$, Israel PZ. Initial radiation experience evaluating early tolerance and toxicities in patients undergoing accelerated partial breast irradiation using the Contura Multi-Lumen Balloon breast brachytherapy catheter. Brachytherapy. 2009;8(2):227-33. doi:10.1016/j.brachy.2008.11.013.

21. Scanderbeg DJ, Yashar C, Rice R, Pawlicki T. Clinical implementation of a new HDR brachytherapy device for partial breast irradiation. Radiother Oncol. 2009;90(1):36-42. doi:10.1016/j.radonc.2008.09.024.

22. Gurdalli S, Kuske RR, Quiet CA, Ozer M. Dosimetric performance of strut-adjusted volume implant: a new single-entry multicatheter breast brachytherapy applicator. Brachytherapy. 2011;10(2):128-35. doi:10.1016/j.brachy.2010.03.002.

23. Vargo JA, Verma V, Kim H, Kalash R, Heron DE, Johnson R, et al. Extended (5-year) outcomes of accelerated partial breast irradiation using MammoSite balloon brachytherapy: patterns of failure, patient selection, and dosimetric correlates for late toxicity. Int J Radiat Oncol Biol Phys. 2014;88(2):285-91. doi:10.1016/j.jirobp.2013.05.039.

24. Bratengeier K, Oechsner M, Gainey M, Flentje M. Remarks on reporting and recording consistent with the ICRU reference dose. Radiat Oncol. 2009;4:44. doi:10.1186/1748-717X-4-44.

25. Arthur DW, Vicini FA, Todor DA, Julian TB, Cuttino LW, Mukhopadhyay ND. Contura Multi-Lumen Balloon breast brachytherapy catheter: comparative dosimetric findings of a phase 4 trial. Int J Radiat Oncol Biol Phys. 2013;86(2):264-9. doi:10.1016/j.ijrobp.2013.01.005.

26. Offersen BV, Overgaard M, Kroman N, Overgaard J. Accelerated partial breast irradiation as part of breast conserving therapy of early breast carcinoma: a systematic review. Radiother Oncol. 2009;90(1):1-13. doi:10.1016/j.radonc.2008.08.005.

27. Polgar C, Van Limbergen E, Potter R, Kovacs G, Polo A, Lyczek J, et al. Patient selection for accelerated partial-breast irradiation (APBI) after breast-conserving surgery: recommendations of the Groupe Europeen de CurietherapieEuropean Society for Therapeutic Radiology and Oncology (GEC-ESTRO) breast cancer working group based on clinical evidence (2009). Radiother Oncol. 2010;94(3):264-73. doi:10.1016/j.radonc.2010.01.014.

28. Sauer G, Strnad V, Kurzeder C, Kreienberg R, Sauer R. Partial breast irradiation after breast-conserving surgery. Strahlenther Onkol. 2005;181(1):1-8. doi:10.1007/s00066-005-1394-7.

29. Strauss JB, Dickler A. Accelerated partial breast irradiation utilizing balloon brachytherapy techniques. Radiother Oncol. 2009;91(2):157-65. doi:10.1016/j.radonc.2008.12.014.

30. Weed DW, Edmundson GK, Vicini FA, Chen PY, Martinez AA. Accelerated partial breast irradiation: a dosimetric comparison of three different techniques. Brachytherapy. 2005;4(2):121-9. doi:10.1016/j.brachy.2004.12.005.

31. Wazer DE, Kaufman S, Cuttino L, DiPetrillo T, Arthur DW. Accelerated partial breast irradiation: an analysis of variables associated with late toxicity and long-term cosmetic outcome after high-dose-rate interstitial brachytherapy. Int J Radiat Oncol Biol Phys. 2006;64(2):489-95. doi:10.1016/j.ijrobp.2005.06.028.

32. Kini V. Balloon breast brachytherapy-review of current data. Brachytherapy. 2005;4(3):181-2. doi:10.1016/j.brachy.2005.07.003.

33. White J. MammoSite and accelerated partial breast irradiation: rethinking one-size-fits-all breast irradiation after lumpectomy. Brachytherapy. 2005;4(3):183-5. doi:10.1016/j.brachy.2005.07.001.

34. Chao KK, Vicini FA, Wallace M, Mitchell C, Chen P, Ghilezan M, et al. Analysis of treatment efficacy, cosmesis, and toxicity using the MammoSite breast brachytherapy catheter to deliver accelerated partial-breast irradiation: the William Beaumont Hospital experience. Int J Radiat Oncol Biol Phys. 2007;69(1):32-40. doi:10.1016/j.jirobp.2007.02.026.

35. Brown S, McLaughlin M, Pope DK, Haile K, Hughes L, Israel PZ, et al. A dosimetric comparison of the Contura multilumen balloon breast brachytherapy catheter vs. the single-lumen MammoSite balloon device in patients treated with accelerated partial breast irradiation at a single institution. Brachytherapy. 2011;10(1):68-73. doi:10.1016/j.brachy.2010.01.001.

36. Patel R, Wong G, Tran L, et al. Multi-lumen hybrid breast brachytherapy: Strut versus balloon-Dosimetric results in first 100 patients. Brachytherapy. 2010;9:S32-S3. 